University of Nebraska - Lincoln

DigitalCommons@University of Nebraska - Lincoln

USDA Forest Service / UNL Faculty Publications U.S. Department of Agriculture: Forest Service -National Agroforestry Center

2013

Evaluating population connectivity for species of conservation concern in the American Great Plains

Samuel A. Cushman

USDA Forest Service, scushman@fs.fed.us

Erin L. Landguth

University of Montana

Curtis $\mathrm{H}$. Flather

USDA Forest Service

Follow this and additional works at: https://digitalcommons.unl.edu/usdafsfacpub

Cushman, Samuel A.; Landguth, Erin L.; and Flather, Curtis H., "Evaluating population connectivity for species of conservation concern in the American Great Plains" (2013). USDA Forest Service / UNL Faculty Publications. 244.

https://digitalcommons.unl.edu/usdafsfacpub/244

This Article is brought to you for free and open access by the U.S. Department of Agriculture: Forest Service -National Agroforestry Center at DigitalCommons@University of Nebraska - Lincoln. It has been accepted for inclusion in USDA Forest Service / UNL Faculty Publications by an authorized administrator of DigitalCommons@University of Nebraska - Lincoln. 


\title{
Evaluating population connectivity for species of conservation concern in the American Great Plains
}

\author{
Samuel A. Cushman • Erin L. Landguth • Curtis H. Flather
}

Received: 20 July 2012/ Accepted: 23 July 2013

(c) Springer Science+Business Media Dordrecht (outside the USA) 2013

This article is a U.S. government work, and is not subject to copyright in the United States.

\begin{abstract}
Habitat loss and fragmentation are widely recognized as among the most important threats to global biodiversity. New analytical approaches are providing an improved ability to predict the effects of landscape change on population connectivity at vast spatial extents. This paper presents an analysis of population connectivity for three species of conservation concern [swift fox (Vulpes velox); lesser prairie-chicken (Tympanuchus pallidicinctus); massasuaga (Sistrurus catenatus)] across the American Great Plains region. We used factorial least-cost path and resistant kernel analyses to predict effects of landscape conditions on corridor network connectivity. Our predictions of population connectivity provide testable hypotheses about the location of core habitats, corridors, and barriers to movement. The results indicate that connectivity is more sensitive to a species' dispersal ability than variation in landscape resistance to movement. Thus, it may prove difficult to optimize conservation strategies to maintain population connectivity for multiple species with disparate dispersal abilities and independent distributions.
\end{abstract}

Keywords Connectivity $\cdot$ Resistant kernel $\cdot$ UNICOR $\cdot$ Swift fox $\cdot$ Lesser prairie chicken $\cdot$ Massasauga

S. A. Cushman $(\bowtie)$

Rocky Mountain Research Station, USDA Forest Service, 2500 South Pine Knoll Dr.,

Flagstaff, AZ 86001, USA

e-mail: scushman@fs.fed.us

E. L. Landguth

Computational Ecology Laboratory, Division of Biological Sciences, University of Montana,

32 Campus Dr., Missoula, MT 59812, USA

C. H. Flather

Rocky Mountain Research Station, USDA Forest Service, 240 West Prospect Road, Fort Collins, CO 80526, USA 


\section{Introduction}

It has proven challenging to reliably predict population connectivity (Rudnick et al. 2012; Cushman et al. 2013). Much of this difficulty is due to uncertainty about species distributions, how different landscape features affect movement, and limited understanding of species dispersal abilities (e.g. Cushman 2006). In addition, there are significant technical challenges in producing fine-scale, spatially explicit predictions of population connectivity across large geographical extents. However, new analytical approaches from the discipline of landscape ecology have improved scientists' abilities to predict effects of landscape structure and fragmentation on population connectivity. For example, resistant kernel (Compton et al. 2007; Cushman et al. 2010a; Landguth et al. 2012) and least-cost path approaches (Cushman et al. 2009, 2010b; Landguth et al. 2012), coupled with landscape pattern analysis (McGarigal et al. 2002), provide a framework to predict the location of core habitats, fracture zones (where connectivity is attenuated by barriers or cumulative dispersal cost), and movement corridors across a range of dispersal abilities (e.g. Cushman et al. 2010a, b).

This project was designed to predict and map core habitat and fracture zones, and identify potential movement corridors for three species of conservation concern in the American Great Plains. Swift fox (Vulpes velox) lesser prairie-chicken (Tympanuchus pallidicinctus) and massasuaga (Sistrurus catenatus) are identified as species of conservation concern across the Great Plain Region. Reliable knowledge about population distribution and connectivity is essential to guide effective conservation actions for these species.

We used resistant kernel (Compton et al. 2007; Cushman et al. 2010a) and least-cost path approaches (Cushman et al. 2009, 2010b) to evaluate habitat area, fragmentation, and corridor connectivity for these three species across the full extent of the Great Plains Landscape Conservation Cooperative. We had three specific objectives: (1) estimate the extent of connected habitat and map dispersal corridors among core habitat patches; (2) identify key geographical locations that are most important to maintaining population connectivity and facilitating movement; (3) evaluate how well protecting areas important for population connectivity for one species could simultaneously protect population connectivity for the others.

The results of connectivity analyses such as those presented here are highly dependent on accurate distribution data, accurate estimates of dispersal distance, and accurate mapping of relative landscape resistance to movement. Given that there is uncertainty in these parameters, results should be interpreted with care and treated as hypotheses warranting further evaluation. However, the connectivity modeling approaches described here enable researchers to make efficient use of existing information to assess connectivity and identify or prioritize areas for management and protection.

\section{Methods}

Study area and focal species

The Great Plains Landscape Conservation Cooperative (GPLCC) is an applied conservation partnership intended to provide science and decision-support tools for the full complement of plant, fish and wildlife resources in the Great Plains geographical area (www. greatplainslcc.org/). The geographic area of the GPLCC encompasses parts of eight states 
including New Mexico, Texas, Oklahoma, Colorado, Kansas, Nebraska, South Dakota, and Wyoming. Some of the most endangered habitats in the US are found in this area, along with a number of imperiled species. Our analysis covers the full extent of the GPLCC, making it one of the largest-scale connectivity modeling efforts undertaken in the United States.

We selected three focal species from the species of greatest conservation concern lists specified in the State Wildlife Action Plans of the states within the GPLCC (www. wildlifeactionplan.org/). Swift fox (Vulpes velox), lesser prairie-chicken (Tympanuchus pallidicinctus), and massasauga (Sistrurus catenatus) were chosen because they are species of high regional conservation concern, they cover a broad taxonomic range, and represent a wide range of dispersal abilities. We used all records since 1970 in the NatureServe (www. natureserve.org) database for these species and for which precise locational data were available. These data provided 3,567 occurrence records of lesser prairie-chicken, 8,454 records of swift fox, and 2,441 records of massasauga within the study area. NatureServe provides a network of biological inventories in all 50 U.S. states, Canada, Latin America and the Caribbean. NatureServe collects and manages detailed information on occurrence records for plants, animals, and ecosystems. Given the large extent of our study area, and the fact that it spans multiple State, federal and local jurisdictions, we chose to use NatureServe because it is the only occurrence database that was compiled using standardized protocols across the full extent of our study area that provides spatial locations for observations.

\section{Landscape resistance hypotheses}

We defined a series of movement resistance models for each focal species based on a combination of biome-level vegetation (Neilson and Draypek 1998), roads (http://www. ipcsr.umich.edu/cocoom/TIGER), landuse and landcover (http://mrlc.gov/nlcd.php). As all three focal species are associated with grassland, we used the same resistance maps for all species. We defined three potential resistance models consisting of a combination of biome-level vegetation and three levels of resistance due to roads and landuse/landcover (Table 1). These three levels represent low, medium and high relative avoidance of crossing roads and non-natural vegetation land cover classes.

We obtained road data from the TIGER/Line shapefiles database, produced by the US Census Bureau. We merged all the TIGER/Line shapefiles for the study area extent, and reprojected to an Albers conformal conic projection. This roads coverage was then transformed from a vector to a raster coverage at a $30 \mathrm{~m}$ pixel grain, and reclassified to four different classes of roads: (1) primary highway with limited access, (2) primary road without limited access, (3) secondary and connecting road, (4) local, neighborhood and rural road. These four classes of road were then reclassified to the relative resistance values shown in Table 1 for the low, medium and high relative resistance scenarios. To facilitate connectivity analysis across very large spatial extents, these $30 \mathrm{~m}$ grain roads raster layers were resampled with bilinear interpolation to a $1 \mathrm{~km}$ pixel size. Resampling with bilinear interpolation retains the net resistant effect across the merged pixels and is an appropriate method to coarsen resistance maps while preserving the spatial pattern of resistance to movement (Cushman and Landguth 2010).

We obtained landcover and landuse data from the National Landcover Database (Fry et al. 2009), produced by the Multi-Resolution Land Characterization (MRLC) consortium. NLCD2001 is a 16-class land cover classification scheme that has been applied consistently across all 50 United States and Puerto Rico at a spatial resolution of $30 \mathrm{~m}$. NLCD2001 is based primarily on the unsupervised classification of Landsat Enhanced 
Table 1 Classification of resistance values in the resistance maps used in our analysis

\begin{tabular}{|c|c|c|c|}
\hline \multirow[t]{2}{*}{ Land attribute } & \multicolumn{3}{|c|}{ Assigned resistance level } \\
\hline & Low & Medium & High \\
\hline \multicolumn{4}{|l|}{ Land cover ${ }^{\mathrm{a}}$} \\
\hline $\begin{array}{l}\text { Natural Perennial ice/Snow; Barren land; Deciduous forest; } \\
\text { Evergreen forest; Mixed forest; Scrub/Shrub; Herbaceous; } \\
\text { Emergent herbaceous wetlands }\end{array}$ & 1 & 1 & 1 \\
\hline Agricultural Hay/Pasture; Cultivated crops & 5 & 10 & 15 \\
\hline Water Open water & 5 & 10 & 15 \\
\hline Residential Developed, open space; Developed, low intensity & 10 & 15 & 20 \\
\hline Urban Developed, medium intensity; Developed, high intensity & 15 & 20 & 25 \\
\hline \multicolumn{4}{|l|}{ Roads $^{b}$} \\
\hline $\begin{array}{l}\text { Primary highway with limited access Interstate highways and } \\
\text { some toll highways are in this category and are distinguished by } \\
\text { the presence of interchanges }\end{array}$ & 200 & 400 & 600 \\
\hline $\begin{array}{l}\text { Primary road without limited access This category consists } \\
\text { mainly of US highways, but may include some state highways } \\
\text { and county highways that connect cities and larger towns }\end{array}$ & 50 & 100 & 150 \\
\hline $\begin{array}{l}\text { Secondary and connecting road This category includes mostly } \\
\text { state highways, but may include some county highways that } \\
\text { connect smaller towns, subdivisions, and neighborhoods }\end{array}$ & 50 & 100 & 150 \\
\hline $\begin{array}{l}\text { Local, neighborhood, and rural road A road in this category is } \\
\text { used for local traffic and usually has a single lane of traffic in } \\
\text { each direction }\end{array}$ & 10 & 10 & 10 \\
\hline \multicolumn{4}{|l|}{ Biome $^{c}$} \\
\hline $\begin{array}{l}\text { Mixed conifer Temperate cool mixed forest, Temperate evergreen } \\
\text { needleleaf woodland, Temperate cool mixed woodland }\end{array}$ & 10 & & \\
\hline $\begin{array}{l}\text { Grass/Shrub Subtropical grassland, Subtropical shrubland, } \\
\text { Temperate grassland; Temperate shrubland }\end{array}$ & 1 & & \\
\hline Desert Subtropical desert & 5 & & \\
\hline Subalpine Tundra; Subalpine & 5 & & \\
\hline
\end{tabular}

${ }^{\text {a }}$ Categorical land cover classes from the 2001 National Land Cover database (http://www.mrlc.gov/nlcd. php)

b Line dataset of roads in the United States from the 2000 Census TIGER line features (http://www.icpsr. umich.edu/cocoon/TIGER/2000ua/states.xml)

c Predicted vegetation cover from 2000 Nielson/Drapek vegetation cover http://www.fs.fed.us/pnw/ corvallis/mdr/mapss)

Thematic Mapper+(ETM+) circa 2001 satellite data. We merged all NLCD2001 tiles for the study area extent and reprojected these layers to an Albers conformal conic projection. We then reclassified the NLCD2001 rasters as shown in Table 1 to produce three levels of relative resistance to movement through different landuse and landcover classes. To facilitate connectivity analysis across very large spatial extents, these $30 \mathrm{~m}$ grain roads raster layers were resampled with bilinear interpolation to a $1 \mathrm{~km}$ pixel size. The three resistance layers used in the analysis (low, medium and high relative resistance) were created by combining the biome, roads and landcover resistance layers through addition (e.g. Cushman et al. 2006).

We replicated all spatial modeling analyses on all three of these resistance layers to quantify the degree to which predictions of population connectivity depended on the 
particular resistance values chosen. Evaluating habitat connectivity across this range of resistance parameters enabled us to quantify the sensitivity of results to variation in the nature of the functional response to landscape composition (as in Cushman et al. 2006) and allowed us to quantify the degree of uncertainty in our predictions.

\section{Connectivity modeling approaches}

This project combined two different connectivity modeling approaches. The first of these approaches is the resistant kernel approach. Unlike most corridor prediction efforts, the resistant kernel approach is spatially synoptic and provides prediction and mapping of expected dispersal rates for every pixel in the study area extent, rather than only for a few selected "linkage zones" (e.g. Compton et al. 2007). Also, in resistant kernel modeling, scale dependency of dispersal ability can be directly included to assess how species of different vagilities may be affected by landscape fragmentation (e.g. Cushman et al. 2010a). Resistant kernel modeling is also computationally efficient, enabling simulation and mapping across the entire GPLCC for multiple species (e.g. Cushman et al. 2010a).

The second approach is a factorial implementation of least-cost path analysis (e.g. Cushman et al. 2009, 2010b; Landguth et al. 2012). We used the universal corridor network simulator (UNICOR; Landguth et al. 2012) to predict movement corridors for each focal species. UNICOR's key features include a driver-module framework, connectivity mapping with thresholding and buffering, and graph theory metrics. Through parallelprocessing computational efficiency is greatly improved allowing analysis of larger geographic extents and populations. Previous least-cost path mapping approaches were limited by prolonged computational times and poor algorithmic efficiency that restricted the size of the conservation problem that could be analyzed, or required artificial subsamples of target populations.

\section{Details of the resistant kernel approach}

The resistant kernel approach to connectivity modeling is based on least-cost dispersal from a defined set of sources. The sources in our case are the locations of NatureServe records of occurrence for the three focal species. Each of the three resistance maps described above provide resistance values for all locations in the study area, in the form of the cost of crossing that pixel relative to the least-cost condition. These costs are used as weights in the dispersal function, such that the expected density of dispersing individuals in a pixel is down-weighted by the cumulative cost from the source, following the least-cost route (Compton et al. 2007). The initial expected density for our three focal species was set to 1 in each cell containing a NatureServe record. The model calculates the expected relative density of each species in each pixel around the source, given the dispersal ability of the species, the nature of the dispersal function, and the resistance of the landscape (Compton et al. 2007; Cushman et al. 2010a). We wrote an ESRI ArcGrid script to calculate the resistant kernel $\left(R_{k}\right)$ density. The script uses the ArcGrid COSTDISTANCE (ESRI 2008) function to produce a map of the movement cost from each source up to the specified dispersal threshold. These cost-distance grids were inverted and scaled such that the maximum value for each individual kernel was one. The scaled kernels surrounding all sources were then summed to give the total expected relative density of dispersing individuals at each pixel. The results of the model were surfaces of expected density of dispersing organisms at any location in the landscape. 
Table 2 Range of dispersal distances for the three focal species used to examine connectivity in the GPLCC

\begin{tabular}{lll}
\hline Species & $\begin{array}{l}\text { Dispersal distance } \\
\text { settings (km) }\end{array}$ & Sources \\
\hline $\begin{array}{l}\text { Lesser prairie-chicken } \\
\text { (Tympanuchus pallidicinctus) }\end{array}$ & $20,40,80$ & $\begin{array}{c}\text { Hagen and Giesen (2005), } \\
\text { Robb and Schroeder (2005) }\end{array}$ \\
$\begin{array}{l}\text { Massasauga (Sistrurus catenatus) } \\
\text { Swift fox (Vulpes velox) }\end{array}$ & $2,4,6$ & $\begin{array}{c}\text { Mackessy (2005), Clark et al. (2008) } \\
\text { Mercure et al. (1993), Dark-Smiley and } \\
\text { Keinath (2003), Kamler et al. (2004) }\end{array}$ \\
\hline
\end{tabular}

We bracketed the range of plausible dispersal abilities of the three focal species (Table 2). The dispersal distance settings for each species were based on careful review of published dispersal distance data in the scientific literature. For the lesser prairie-chicken, Hagen and Giesen (2005) reported that $7 \%$ of 348 movements by individuals of this species in SW Kansas exceeded $30 \mathrm{~km}$. Robb and Schroeder (2005) report that lesser prairie-chicken individuals are capable of long distance movements. They believe there are no natural barriers impeding the connectivity of lesser prairie-chicken populations throughout most of their range. Based on the observed frequency of dispersal greater than $30 \mathrm{~km}$, we chose three dispersal distances for the lesser prairie-chicken which likely bracket the functional range of dispersal in this species. The three dispersal distances were 20000,40000 , and 80000 cost units, reflecting a range of $20-80 \mathrm{~km}$ of dispersal ability in optimal habitat.

Mackessy (2005) reports that over the course of the active season, massasaugas moved considerable distances. Data from three individuals indicated that total distance of movements may be $2-4 \mathrm{~km}$. Clark et al. (2008) report that massasaugas exhibit population genetic structure over very short distances (1-2 km), indicating either extremely limited natal dispersal, reduced movement associated with mating, or both. Accordingly, we chose dispersal distances for massasauga of 2000, 4000, and 6000 cost units, corresponding to dispersal ability in optimal habitat of between 2 and $6 \mathrm{~km}$.

Dark-Smiley and Keinath (2003) reported dispersal distances for adult swift foxes averaging $11 \mathrm{~km}$, with an observed maximum distance of $64 \mathrm{~km}$ (Mercure et al. 1993). Kamler et al. (2004) report movement of one female swift fox as far as $20 \mathrm{~km}$, before returning to her natal range where she remained philopatric. Based on these published movement abilities we chose dispersal distances for swift fox of 10000, 30000, and 60000 cost units, corresponding to dispersal ability of $10-60 \mathrm{~km}$ in optimal habitat. It should be noted that these dispersal distances are effectively "maximum dispersal distance" in the resistant kernel modeling approach, and the vast majority of modeled dispersal events will be less than half that total cost distance using the resistant kernel method.

\section{Details of the least-cost path approach}

The UNICOR simulator uses Dijkstra's algorithm (Dijkstra 1959) to solve the single source shortest path problem from every mapped species occurrence location on a landscape to every other occurrence location (Landguth et al. 2012). The analysis produces predicted least-cost path routes from each source point to each destination point. UNICOR requires two input files: (1) a landscape resistance surface, and (2) point locations for each population or individual's location. Point locations define starting and ending nodes of the least-cost paths between pairs of individuals. From graph theory and network analysis, we 
can then represent the landscape resistance surface as a graph with nodes and edges. Each occurrence record was considered to be a node. The graph edges, which represent possible movement paths between each node were weighted by the resistance value of the cell, times the distance to the next pixel center, which gives the total edge length in terms of raster cell units (resistance distance). Dijkstra's algorithm was then implemented to find optimal paths of movement, computed for every paired combination of starting and ending nodes. These predicted least-cost paths were buffered based on kernel density estimations (e.g. Cushman et al. 2008). A choice of a Gaussian function was used for the kernel density buffering (as in Li and Racine 2007). The buffered least-cost paths were then combined through summation (as in Cushman et al. 2009) to produce maps of connectivity networks among all pairs of sources and destinations.

\section{Analyzing extent and connectivity of habitat}

The analyses described above produced 27 connectivity maps, with nine produced for each focal species, corresponding to the factorial combination of the three dispersal abilities and the three levels of relative landscape resistance (high, med, low). In their raw form these maps depict the expected density of dispersing individuals. These densities indicate the distribution of connected populations (where the cells are predicted to contain non-zero occupancy rates for each species) and the spatial variation in expected densities of dispersers. These two attributes are the foundation for analyses of population distribution, identification of core habitats, fracture zones, and barriers to dispersal.

We defined barriers as locations where the resistant kernel predictions became zero (no movement) between core habitat patches. We defined core habitat patches as contiguous units with limited restrictions on animal movement as indicated by resistant kernel values greater than $10 \%$ of the highest recorded for the species. We defined fracture zones as locations where the resistant kernel predictions were

$$
0<R_{k}<10 \% \text { of maximum. }
$$

Thus, we defined fracture zones as areas between core habitat patches where occupancy and internal movement rates were less than $10 \%$ of the value of the highest recorded for the species. The upper limit of $R_{k}$ that defines a fracture zone is arbitrary and represents the area of the landscape in which the expected density of individuals is less than $10 \%$ of the maximum density. Total connected habitat is all areas where the resistant kernel predicted values are greater than zero (core + fracture zones).

\section{FRAGSTATS metrics}

We used FRAGSTATS (McGarigal et al. 2002) to calculate the percentage of the landscape, correlation length, largest patch index, and number of patches that are predicted to be connected habitat or core habitat (the latter being a spatial subset of the former) for each focal species. The percentage of the landscape is the simplest metric of landscape composition, and quantifies how much of the study area is predicted to be connected or core habitat for each species. Correlation length provides a measure of the average distance an organism can move within a patch before encountering the patch boundary from a random starting point (McGarigal et al. 2002). The correlation length gives a global measure of the connectivity of the landscape and is a more relevant functional measure of habitat availability than more basic measures such as patch size, nearest neighbor distance, and 
percentage of the landscape in occupied habitat (McGarigal et al. 2002). Third, we calculated the largest patch index (McGarigal et al. 2002) of both predicted connected and core habitat. This index reports the extent, as a proportion of the size of the study area, of the largest patch of connected or core habitat. Fourth, we calculated the number of patches of internally connected habitat for each species across the combination of dispersal ability and relative landscape resistance.

\section{Multiple species connectivity}

We also conducted further analyses to identify the areas that are predicted to be barriers and fracture zones simultaneously for the three focal species. Management actions will likely have larger overall benefit if they simultaneously address the ecological needs of multiple species of concern (Beier and Brost 2010). We intersected the resistant kernel predictions of all connected habitat, core habitat and fracture zones across the three species for each combination of dispersal ability and relative landscape resistance.

\section{Results}

Lesser prairie-chicken

We mapped nine different alternative models for lesser prairie-chicken habitat connectivity, consisting of the factorial of relative landscape resistance (high, med, low) and dispersal ability $(20,40,80 \mathrm{~km})$. Results for medium relative landscape resistance and $40 \mathrm{~km}$ dispersal ability are shown in Fig. 1. We chose to illustrate this combination as it is the intermediate prediction that we feel best reflects the probable pattern of population connectivity of the species. Maps of predicted connected habitat for all nine combinations of connected relative landscape resistance and dispersal ability for lesser prairie-chicken are available for download (http://cel.dbs.umt.edu/cms/index.php/lesserprairiechicken/ chickendetails).

In Fig. 1, predicted "core" habitat is shown in red patches and "fracture zones" of attenuated connectivity are shown in blue patches. Total area of habitat predicted to be connected by dispersal is the union of the core habitat and the fracture zone patches. The figure shows that predicted connected lesser prairie-chicken habitat at the Med $\times 40 \mathrm{~km}$ combination of relative landscape resistance and dispersal ability was concentrated in two regions, one in the southwest, and another in the north-central parts of the study area. The southwest population was predicted to exist in a single connected patch with large areas of core habitat and high internal migration rates. The north-central populations were predicted to be broken up into five patches that were predicted to be isolated from one another and from the southwestern population. We predicted a relatively large area of core habitat with high internal migration rates in the central patch in the north-central group. However, the eastern most patches were predicted to have weak internal migration rates due to the low number of lesser prairie-chicken location records from that area in the NatureServe database used to populate the model.

The dispersal corridors predicted by the UNICOR model are shown in an orange colorramp, with dark orange corresponding to areas that were predicted to be the strongest corridors. Figure 1 shows two dominant dark orange corridors connecting the southern 
Fig. 1 Lesser prairie-chicken dispersal corridors and habitat connectivity for the resistance map GHRMLM, corresponding to grassland associated species with medium relative resistance due to roads and landuse. The map shows resistant kernel core habitat areas (red) and fracture zones (blue) overlaying the UNICOR corridor pathways [gradient from weak (light orange) to strong (dark orange)]. The boundary of the Great Plains Landscape Conservation Cooperative boundary is shown in dark black line. Interstate highways are shown in green lines

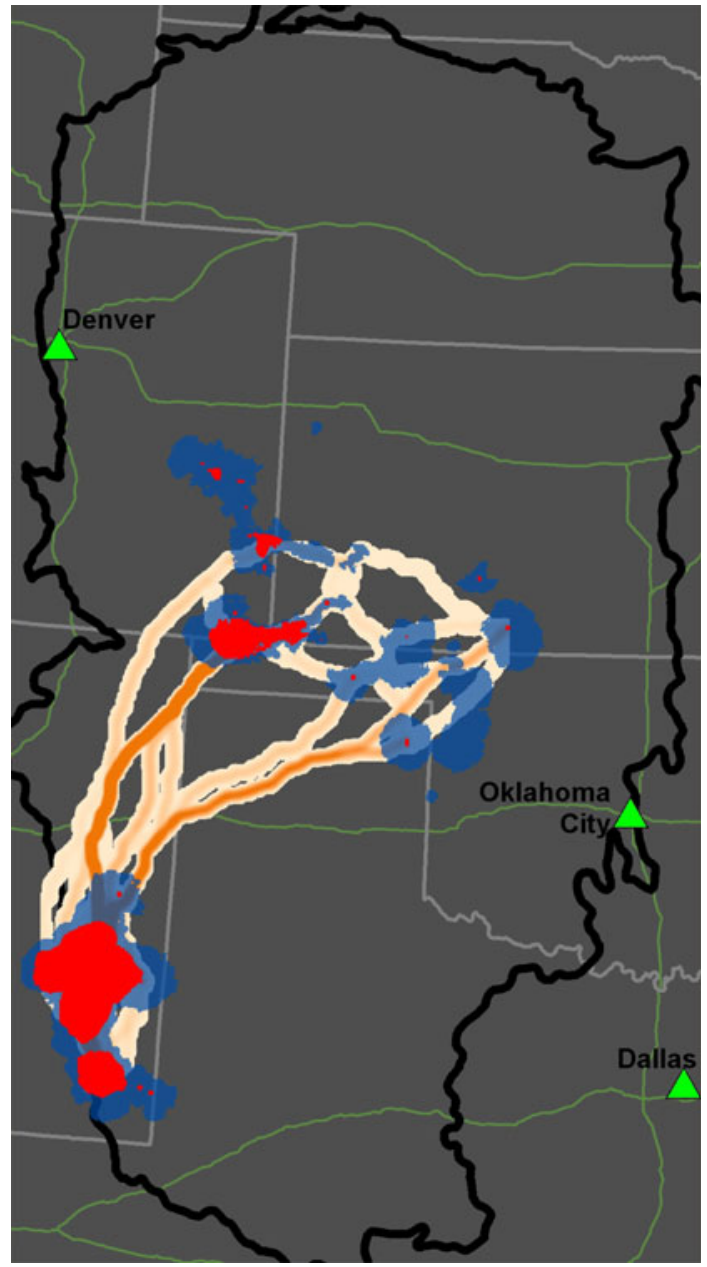

patch of core habitat to the north central core population and the eastern cluster of subpopulations. There are corridors of lesser strength connecting the other subpopulations.

We calculated four FRAGSTATS metrics of landscape composition and configuration on the connected habitat maps for all nine combinations for relative landscape resistance and dispersal ability for lesser prairie-chicken connected habitat (Table 3). Predicted core habitat comprised about $1 / 3$ the total area of connected habitat, and had roughly half the connectivity as measured by correlation length and largest patch index. The percentage of the landscape, correlation length and largest patch index of connected habitat were predicted to increase greatly, and the number of patches was predicted to decrease, with increasing dispersal ability (Table 3). In contrast, extent and connectivity of habitat was predicted to be largely independent of the relative values of landscape resistance used in our analysis. Sensitivity analysis confirmed this finding with landscape metrics showing relatively low sensitive to landscape resistance levels when compared to dispersal ability (Table 4). 
Table 3 FRAGSTATS results for percentage of landscape in connected habitat (PLAND), largest patch of connected habitat percentage of study area (LPI), correlation length of connected habitat (CL), and number of individual patches of connected habitat (NP) across factorial combination of three levels of relative landscape resistance (high, med, low) and three levels of dispersal ability (20000, 40000, 80000 cost units) for the lesser prairie-chicken

\begin{tabular}{|c|c|c|c|c|c|c|c|}
\hline \multirow{3}{*}{$\begin{array}{l}\text { FRAGSTAT } \\
\text { metric }\end{array}$} & \multirow{3}{*}{$\begin{array}{l}\text { Landscape } \\
\text { resistance }\end{array}$} & \multicolumn{6}{|c|}{ Dispersal ability (cost units) } \\
\hline & & \multicolumn{2}{|l|}{20,000} & \multicolumn{2}{|l|}{40,000} & \multicolumn{2}{|l|}{80,000} \\
\hline & & Core & Connected & Core & Connected & Core & Connected \\
\hline \multirow[t]{3}{*}{ PLAND } & High & 0.68 & 2.39 & 1.30 & 5.13 & 2.51 & 10.74 \\
\hline & Med & 0.71 & 2.53 & 1.38 & 5.50 & 2.66 & 11.55 \\
\hline & Low & 0.77 & 2.76 & 1.50 & 6.11 & 2.90 & 12.77 \\
\hline \multirow[t]{3}{*}{ NP } & High & 31 & 25 & 24 & 12 & 18 & 4 \\
\hline & Med & 28 & 25 & 22 & 12 & 18 & 3 \\
\hline & Low & 26 & 22 & 21 & 10 & 16 & 3 \\
\hline \multirow[t]{3}{*}{ CL } & High & 21129.95 & 37269.38 & 30371.50 & 53830.22 & 56664.74 & 127731.1 \\
\hline & Med & 21205.94 & 37122.96 & 30807.03 & 54081.76 & 57089.12 & 127936.5 \\
\hline & Low & 21180.72 & 39961.27 & 31417.42 & 58962.21 & 57552.61 & 127535.4 \\
\hline \multirow[t]{3}{*}{ LPI } & High & 0.34 & 1.17 & 0.813 & 2.20 & 2.03 & 6.71 \\
\hline & Med & 0.35 & 1.19 & 0.838 & 2.27 & 2.11 & 7.34 \\
\hline & Low & 0.36 & 1.31 & 0.87 & 2.38 & 2.21 & 8.30 \\
\hline
\end{tabular}

Connected value of the metric for the full extent of habitat connected by the resistant kernel modeling. Core value of the metric for the portion of the resistant kernel predictions in "core" habitat

Table 4 Relative sensitivity of landscape metrics (PLAND, percentage of landscape in connected habitat; CL, correlation length of connected habitat; LPI, largest patch of connected habitat percentage of study area; $\mathrm{NP}$, number of individual patches) to variation in landscape resistance levels and dispersal ability for each focal species

\begin{tabular}{|c|c|c|c|c|c|c|c|c|}
\hline \multirow{2}{*}{$\begin{array}{l}\text { Focal } \\
\text { species }\end{array}$} & \multicolumn{2}{|l|}{ PLAND } & \multicolumn{2}{|l|}{$\mathrm{CL}$} & \multicolumn{2}{|l|}{ LPI } & \multicolumn{2}{|l|}{ NP } \\
\hline & $\begin{array}{l}\text { Landscape } \\
\text { resistance }\end{array}$ & $\begin{array}{l}\text { Dispersal } \\
\text { ability }\end{array}$ & $\begin{array}{l}\text { Landscape } \\
\text { resistance }\end{array}$ & $\begin{array}{l}\text { Dispersal } \\
\text { ability }\end{array}$ & $\begin{array}{l}\text { Landscape } \\
\text { resistance }\end{array}$ & $\begin{array}{l}\text { Dispersal } \\
\text { ability }\end{array}$ & $\begin{array}{l}\text { Landscape } \\
\text { resistance }\end{array}$ & $\begin{array}{l}\text { Dispersal } \\
\text { ability }\end{array}$ \\
\hline $\begin{array}{l}\text { Lesser } \\
\text { prairie- } \\
\text { chicken }\end{array}$ & 0.085 & 1.137 & 0.030 & 0.880 & 0.070 & 1.562 & 0.089 & 0.617 \\
\hline Swift fox & 0.080 & 1.129 & 0.082 & 1.394 & 0.113 & 4.293 & 0.195 & 0.612 \\
\hline Massasauga & 0.039 & 0.428 & 0.028 & 0.183 & 0.072 & 0.621 & 0.036 & 0.222 \\
\hline
\end{tabular}

\section{Swift fox}

We mapped nine alternative models of habitat connectivity for swift fox, consisting of the factorial of relative landscape resistance (high, med, low) and dispersal ability (10, 30, $60 \mathrm{~km}$ ). The results for medium relative resistance and $30 \mathrm{~km}$ dispersal ability scenario are shown in Fig. 2. Maps of predicted connected habitat for all nine combinations of connected relative landscape resistance and dispersal ability for Swift fox are available for download at http://cel.dbs.umt.edu/cms/index.php/swiftfox/foxdetails. 


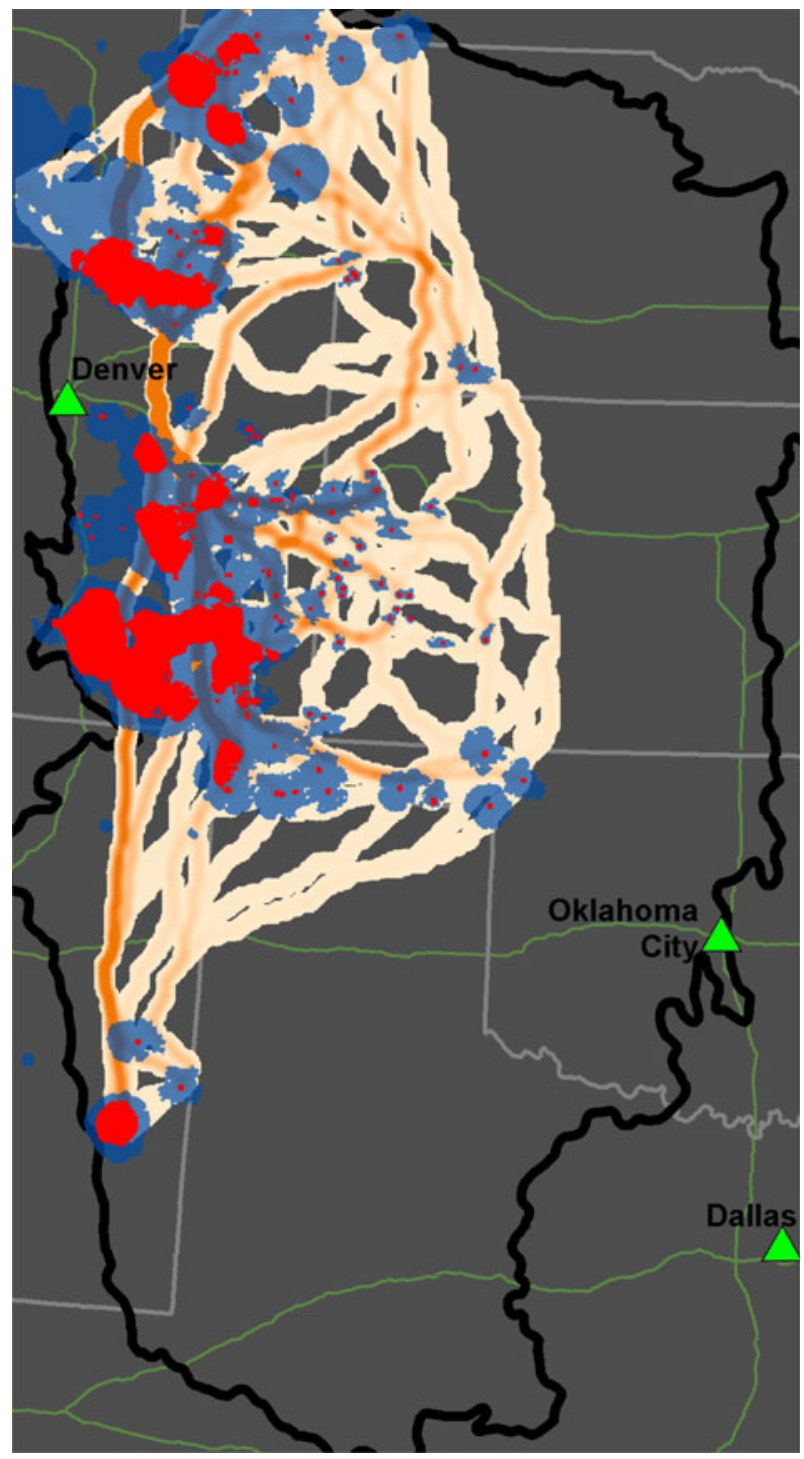

Fig. 2 Swift fox dispersal corridors and habitat connectivity for the resistance map GHRMLM, corresponding to grassland associated species with medium relative resistance due to roads and landuse. The map shows resistant kernel core habitat areas ( red) and fracture zones (blue) overlaying the UNICOR corridor pathways. The boundary of the Great Plains Landscape Conservation Cooperative boundary is shown in dark black line. Interstate highways are shown in green lines

Swift fox habitat at the Med $\times 30 \mathrm{~km}$ combination of relative landscape resistance and dispersal ability was predicted to be relatively widespread across the northwestern $1 / 3$ of the study area, with four large core habitat concentrations (Fig. 2). The northernmost populations were predicted to be broken up into two major centers and several smaller subpopulations were predicted to be isolated from one another. The large west-central area was predicted to be largely connected into a single large patch containing several large 
Table 5 FRAGSTATS results for percentage of landscape in connected habitat (PLAND), largest patch of connected habitat percentage of study area (LPI), correlation length of connected habitat (CL), and number of individual patches of connected habitat (NP) across factorial combination of three levels of relative landscape resistance (high, med, low) and three levels of dispersal ability (10000, 30000, 60000 cost units) for the swift fox

\begin{tabular}{|c|c|c|c|c|c|c|c|}
\hline \multirow{3}{*}{$\begin{array}{l}\text { FRAGSTAT } \\
\text { metric }\end{array}$} & \multirow{3}{*}{$\begin{array}{l}\text { Landscape } \\
\text { resistance }\end{array}$} & \multicolumn{6}{|c|}{ Dispersal ability (cost units) } \\
\hline & & \multicolumn{2}{|l|}{10,000} & \multicolumn{2}{|l|}{30,000} & \multicolumn{2}{|l|}{60,000} \\
\hline & & Core & Connected & Core & Connected & Core & Connected \\
\hline \multirow[t]{3}{*}{ PLAND } & High & 1.28 & 4.40 & 2.71 & 11.11 & 6.04 & 18.76 \\
\hline & Med & 1.31 & 4.61 & 2.88 & 11.84 & 6.49 & 20.00 \\
\hline & Low & 1.38 & 5.01 & 3.17 & 13.14 & 7.21 & 22.08 \\
\hline \multirow[t]{3}{*}{ NP } & High & 148 & 114 & 120 & 52 & 84 & 22 \\
\hline & Med & 144 & 112 & 112 & 41 & 85 & 15 \\
\hline & Low & 140 & 95 & 108 & 30 & 75 & 12 \\
\hline \multirow[t]{3}{*}{ CL } & High & 8990.68 & 22280.20 & 32729.71 & 76067.72 & 67448.92 & 109790.70 \\
\hline & Med & 9931.55 & 22165.44 & 35700.49 & 77680.42 & 68799.49 & 111916.60 \\
\hline & Low & 11783.55 & 27465.05 & 39240.69 & 80848.34 & 71451.68 & 130739.70 \\
\hline \multirow[t]{3}{*}{ LPI } & High & 0.131 & 0.59 & 1.177 & 5.15 & 3.70 & 9.11 \\
\hline & Med & 0.133 & 0.60 & 1.267 & 5.52 & 3.94 & 9.91 \\
\hline & Low & 0.208 & 0.73 & 1.380 & 6.19 & 4.37 & 11.42 \\
\hline
\end{tabular}

Connected value of the metric for the full extent of habitat connected by the resistant kernel modeling. Core value of the metric for the portion of the resistant kernel predictions in "core" habitat

core habitat areas with high rates of internal movement, and linked across fracture zones of attenuated movement rates. Finally, there were several isolated subpopulations predicted in the southwestern corner of the study area.

The strongest predicted corridors (dark orange) connect the north, central, and southern core habitat areas in a nearly north-south azimuth (Fig. 2). We also observed an extensive network of weaker corridors connecting the mosaic of small subpopulations in the northern and central cluster to each other and to the core habitats in other parts of the study area.

At all levels of dispersal ability and relative landscape resistance, there was a large change in the FRAGSTATS metrics between analysis of connected habitat and core habitat (Table 5). Specifically, predicted core habitat comprised about $1 / 4$ to $1 / 2$ of the total area of connected habitat, and had roughly $1 / 3$ to $1 / 2$ the connectivity as measured by correlation length and largest patch index. As with the lesser prairie-chicken, the percentage of the landscape, correlation length and largest patch index of connected habitat were predicted to increase greatly, and the number of patches was predicted to decrease, with increasing dispersal ability (Table 5). Also similar to the lesser prairie-chicken results, extent and connectivity of connected swift fox habitat was predicted to be largely independent of the relative values of landscape resistance used in our analysis. For all four landscape metrics, dispersal ability had much greater effect than variation in relative landscape resistance (Table 4).

\section{Massasauga}

We mapped nine alternative models of habitat connectivity for the massasauga, consisting of the factorial of relative landscape resistance (high, med, low) and dispersal ability (2, 4, $6 \mathrm{~km}$ ) for the massasuaga. Figure 3 shows the strong effect of the limited dispersal ability 
Fig. 3 Massasauga dispersal corridors and habitat connectivity for the resistance scenario GHRMLM, corresponding to grassland associated species with medium relative resistance due to roads and landuse. The map shows resistant kernel core habitat areas (red) and fracture zones (blue) overlaying the UNICOR corridor pathways. The boundary of the Great Plains Landscape Conservation Cooperative boundary is shown in dark black line. Interstate highways are shown in green lines

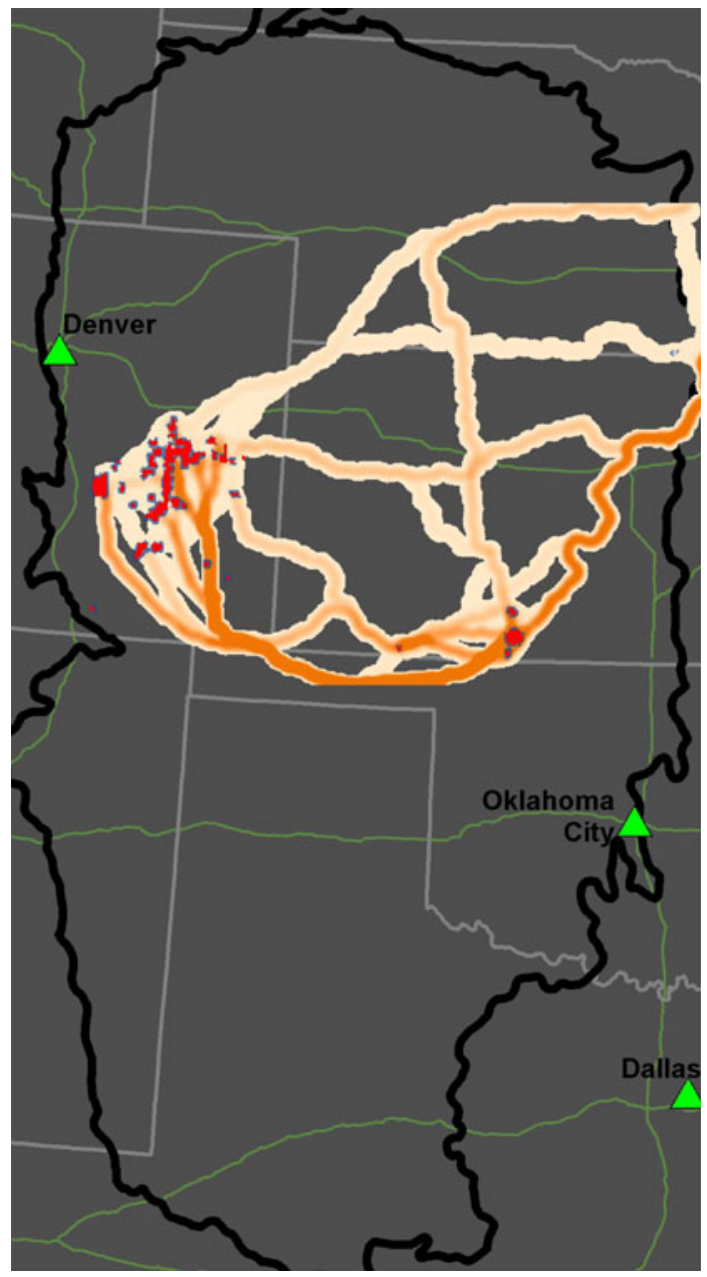

of this species, with connected habitat concentrated in close proximity to the occurrence records taken from the NatureServe database. Maps of predicted connected habitat for all nine combinations of connected relative landscape resistance and dispersal ability for massasauga are available for download (http://cel.dbs.umt.edu/cms/index.php/massasuga/ snakedetail).

The population of this species was concentrated in the west-central area of the study area (Fig. 3). Most of the predicted occurrences were united by dispersal into a single patch, with a number of apparently isolated satellite subpopulations. There were also several small and isolated subpopulations in the central and northeast parts of the study area. Figure 3 also shows the predicted network of corridors that unite core habitat along least-cost routes. There is a single dominant corridor that connects the west-central cluster of core populations to the east-central cluster along a corridor that arcs strongly to the south. There is also a network of corridors of lesser predicted strength connecting the full network of species occurrence records.

In contrast to the previous focal species, there was a relatively small decrease in the FRAGSTATS metrics between analysis of all predicted connected habitat and core habitat 
Table 6 FRAGSTATS results for percentage of landscape in connected habitat (PLAND), largest patch of connected habitat percentage of study area (LPI), correlation length of connected habitat (CL), and number of individual patches of connected habitat (NP) across factorial combination of three levels of relative landscape resistance (high, med, low) and three levels of dispersal ability (2000, 4000, 6000 cost units) for the massasuaga

\begin{tabular}{|c|c|c|c|c|c|c|c|}
\hline \multirow{3}{*}{$\begin{array}{l}\text { FRAGSTAT } \\
\text { metric }\end{array}$} & \multirow{3}{*}{$\begin{array}{l}\text { Landscape } \\
\text { resistance }\end{array}$} & \multicolumn{6}{|c|}{ Dispersal ability (cost units) } \\
\hline & & \multicolumn{2}{|l|}{2,000} & \multicolumn{2}{|l|}{4,000} & \multicolumn{2}{|l|}{6,000} \\
\hline & & Core & Connected & Core & Connected & Core & Connected \\
\hline \multirow[t]{3}{*}{ PLAND } & High & 0.23 & 0.35 & 0.266 & 0.49 & 0.32 & 0.66 \\
\hline & Med & 0.21 & 0.32 & 0.267 & 0.50 & 0.329 & 0.67 \\
\hline & Low & 0.21 & 0.33 & 0.271 & 0.52 & 0.341 & 0.71 \\
\hline \multirow[t]{3}{*}{ NP } & High & 30 & 29 & 30 & 22 & 21 & 19 \\
\hline & Med & 31 & 34 & 30 & 21 & 21 & 19 \\
\hline & Low & 31 & 34 & 30 & 21 & 20 & 19 \\
\hline \multirow[t]{3}{*}{ CL } & High & 13966.87 & 16159.06 & 13970.47 & 18969.24 & 18293.45 & 19879.41 \\
\hline & Med & 13501.83 & 13612.7 & 13983.17 & 18994.64 & 18300.92 & 19855.07 \\
\hline & Low & 13498.96 & 13617.15 & 13890.8 & 18953.08 & 18768.55 & 19781.07 \\
\hline \multirow[t]{3}{*}{ LPI } & High & 0.093 & 0.18 & 0.11 & 0.26 & 0.184 & 0.33 \\
\hline & Med & 0.079 & 0.12 & 0.11 & 0.26 & 0.186 & 0.34 \\
\hline & Low & 0.079 & 0.12 & 0.11 & 0.27 & 0.197 & 0.35 \\
\hline
\end{tabular}

Connected value of the metric for the full extent of habitat connected by the resistant kernel modeling. Core value of the metric for the portion of the resistant kernel predictions in "core" habitat

(Table 6). This decrease reflected the limited dispersal ability of the species, which concentrates patches into core habitat with limited fracture zone area. As in the previous cases, the percentage of the landscape, correlation length and largest patch index of predicted connected habitat increased, and the number of patches decreased, with increasing dispersal ability (Table 6). Also consistent with the previous two species, extent and fragmentation of connected massasauga habitat was predicted to be largely independent of the relative values of landscape resistance used in our analysis. For all four landscape metrics, dispersal ability had more than ten times greater effect than variation in relative landscape resistance (Table 4).

\section{Multiple species connectivity}

We found relatively limited ability to simultaneously optimize protection for connected habitat for all three species (Fig. 4). Specifically, there was relatively little overlap of predicted connected habitat among the three species. Less than $1 / 3$ of the total extent of connected habitat across the three species is simultaneously connected for two of the three species, and less than $10 \%$ provides connected habitat for all three species simultaneously.

\section{Discussion}

Many connectivity assessments have focused on establishing or protecting narrow linear corridors of habitat between core populations (Harris and Gallagher 1989; Beier and Loe 1992; Harrison and Bruna 1999). However, there is considerable doubt regarding the utility 
Fig. 4 Intersection map for predicted connected habitat. The colors depict different species combinations

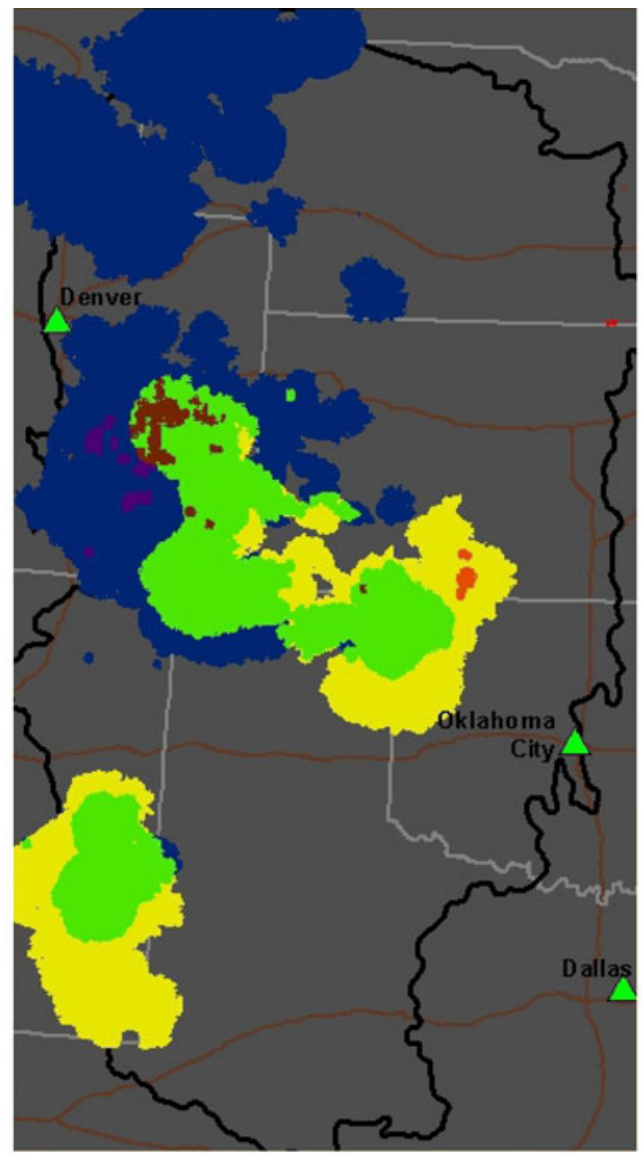

Swift Fox

Massas auga

Lesser Prairie-Chicken

Massas auga and Swift Fox

Lesser Prairie-Chicken and Swift Fox

Lesser Prairie-Chicken and Mass as auga

Lesser Prairie-Chicken, Massas auga, and Swift Fox

of these small, narrow, linear features to provide population subsidization and recolonization among patches (Hobbs 1992; Simberloff et al. 1992; Rosenberg et al. 1997). It is more likely that organisms experience their surroundings as gradients of differential quality in relation to ecological and life-history characteristics (McGarigal and Cushman 2005; Cushman et al. 2009, 2010c). Considering connectivity from this perspective also allows a shift in the scale of focus from linear corridors between patches, which are usually small relative to the vagility of the organism and the distribution of its population, to a broader scale analysis of how landscape patterns of differential resistance to movement affect connectivity at scales relevant to the population-level processes that are central to effective conservation (Berger et al. 2006; Cushman 2006; Cushman et al. 2009). 
We assessed broad scale population connectivity, including the extent and pattern of core habitat areas, the location of fracture zones, barriers and corridors between core habitat patches, which enabled us to integrate the effects of differential sensitivity to landuse and differential dispersal ability on population connectivity. Instead of computing pair-wise corridors between a priori defined sources (e.g. Beier et al. 2007), we combined resistant kernel and factorial least-cost path approaches to predict spatially synoptic patterns of connectivity and identify all-directional dispersal (e.g. Compton et al. 2007; Cushman et al. 2010a, Cushman and Landguth 2012b), providing a more complete picture of connectivity across continuous space. In addition, we evaluated scale dependency across three dispersal distances, corresponding to an eightfold range in dispersal ability, enabling us to evaluate the sensitivity of individual species' connectivity to dispersal ability. By combining a range of alternative resistance models with multiple dispersal distances, we quantified the relationships between dispersal ability and ecological characteristics in driving multi-species connectivity across a large area of the American Great Plains.

There have been few published studies that have utilized spatially synoptic connectivity modeling that incorporated differential dispersal ability. Compton et al. (2007) used the resistant kernel approach to rank vernal pools in Massachusetts by local, neighborhood, and regional connectivity and identify the most functionally connected pool complexes. Cushman et al. (2010a) evaluated effects of changing population size, dispersal ability and landscape resistance on population connectivity of pond breeding amphibians in Massachussetts. They found that population connectivity was a complex interaction between dispersal ability, population size and the landscape factors influencing resistance to movement, highlighting the importance of correctly specifying species dispersal ability and explicitly incorporating it into connectivity analyses.

Similar to Compton et al. (2007) and Cushman and Landguth (2012a, b), our analysis provides mapped predictions of connectivity that could potentially be used to prioritize areas for conservation that maximally protect the total connectivity of the population. Our results also support the findings of Cushman et al. (2010a) who found that dispersal ability played a larger role than relative landscape resistance in affecting the degree of connectivity across resistant landscapes. It is interesting to note that most efforts to delineate corridors or linkage zones have not explicitly addressed the issue of dispersal ability.

Our mapping of core habitat, fracture zones, and corridor areas in the GPLCC for the three focal species indicated that the populations of all three species are fragmented. The massasauga would appear to be the most vulnerable to fragmentation given its highly limited dispersal ability. However, the apparently aggregated distribution of this species may reduce this effect. The main core population appears to be relatively well connected, with a few internal fracture zones and gaps spanned by potentially important corridors. We believe, therefore, that the main risks to massasauga are related to limited population size and area of occupied habitat, and conservation actions may be most effective if they focus primarily on protecting and expanding core habitat areas.

Lesser prairie-chicken and swift fox have relatively large dispersal abilities, which should help mitigate the effects of habitat fragmentation. However, the scale at which the populations of these species are broken into patches may produce severe fragmentation. For both species, the main areas of occupied core habitat are separated by large gaps that are wider than the predicted dispersal abilities of the species, which may increase local extinction risk. For these species, mitigating areas of limited connectivity among core habitat patches and enhancing potential linkage corridors may be nearly as important as protecting core habitat. Protecting core habitat we feel should usually be the first priority, 
but for these species increasing connectivity between isolated core patches also could be critically important.

Multiple-species connectivity: quantifying strength of linkage

Linkage refers to portions of a landscape intended to support the connectivity of multiple focal species and ecosystem processes (Beier and Brost 2010). There have been few evaluations of the efficacy of proposed corridors or linkage zones for multiple species. While Haddad et al. (2003) found that narrow, experimentally created corridors influenced the movement rates of ten focal species, it is unclear the extent to which these short term observations of movement influence population processes such as gene flow and demographic exchange. Beier et al. (2006, 2007) designed large-scale linkage plans in California and Arizona to simultaneously meet the needs of 10-30 focal mammals, reptiles, fishes, amphibians, plants, and invertebrates. However, these efforts did not explicitly model how effective the linkages would be across the range of dispersal abilities of the focal species.

We found relatively limited ability to simultaneously optimize protection for connected habitat for all three species, with little overlap of predicted core habitat among the three species. The inability of one of our three focal species to provide umbrella protection for the others suggests that it will likely be challenging to simultaneously protect these three species in a single multi-species conservation effort. Given their independent distributions and complex patterns of habitat connectivity, it is likely that conservation strategies will have to be optimized for each of these species separately.

Scope and limitations

There are several limitation to this analysis that need to be considered in interpreting the results, including the importance of empirically validating predicted corridors, uncertainty in species responses to landscape composition, uncertainty in species dispersal abilities, and uncertainty in species distributions.

\section{Validating predicted corridors}

Modeled predictions of core habitat areas, fracture zones, and corridors have sometimes been criticized because they lack supporting movement data (Simberloff et al. 1992; Rosenberg et al. 1997) and because they may contain errors in model parameters or incorrect assumptions (Spear et al. 2010). It would be valuable to conduct research to test whether individual animals are preferentially moving through predicted habitat or corridors. One way to test the robustness of our predictions would be to monitor movement of a large number of individuals and statistically evaluate the frequency of movement through predicted connected habitat and corridors relative to availability. In addition, genetic markrecapture or parentage analysis could be used document movement of individuals or parent-offspring pairs through predicted connected habitat or predicted corridors relative to availability.

\section{Uncertainty in landscape resistance}

Most of the published studies using landscape resistance maps have relied on expert opinion to estimate resistance of landscape features to movement (Zeller et al. 2012) given 
the lack of detailed information on animal movement or gene flow for most species. However, basing analyses on unvalidated expert opinions is not desirable (Seoane et al. 2005), and landscapes are perceived by particular species in ways that may not correspond to our assumptions concerning connectivity and habitat quality (With et al. 1997; Wiens 2001; Shirk et al. 2010). We sought to mitigate this uncertainty by evaluating a range of potential landscape resistance parameterizations for each focal species. We recommend further investment of resources to test and validate the resistance maps produced by this analysis using movement (e.g. Short Bull et al. 2011; Cushman and Lewis 2010; Reding et al. 2013) and landscape genetic methods (e.g. Cushman et al. 2006; Wasserman et al. 2010; Shirk et al. 2010).

\section{Uncertainty in dispersal ability}

What constitutes functional connectedness is highly dependent on the dispersal behaviour of the particular species in question. The cumulative cost distances organisms are able to traverse, and the probability distributions of movements as a function of cost distances between sources and potential destinations vary greatly among species. We reviewed the literature on the dispersal abilities of the three focal species, and chose to evaluate three different dispersal distances for each. The goal was to evaluate a "low end", "middle" and "high end" estimate of dispersal ability to quantify the effects of differential mobility on predictions of the extent and connectivity of habitat in the GPLCC. Our results indicate that predictions of the extent and pattern of core habitat areas, and the degree to which they are linked by dispersal are highly sensitive to dispersal ability. In our analysis, variation in dispersal ability was generally 10-20 times more impactful on our predictions than variation in landscape resistance parameterization. Given high sensitivity to dispersal ability, further research is warranted to evaluate the dispersal behaviour and quantify the distribution of dispersal distances for our three study species.

\section{Uncertainty in species distributions}

The methods we employ are based on predicting population cores, fracture zones, and corridors based on modeling dispersal from source locations in the landscape. Therefore, meaningful inferences are conditioned on comprehensive landscape occupancy data for species of interest. Accurate information on the distribution of species is fundamental to reliable predictions. However, obtaining reliable and consistent information of spatial patterns of species distributions is very challenging. We tried to address this uncertainty by utilizing all element occurrences recorded since 1970 in the NatureServe database, which is arguably the best synoptic database of distribution and occurrence across the full GPLCC. However, there are a number of caveats associated with the use of NatureServe's data to document current landscape occupancy patterns including the absence of consistent and systematic inventory methods that can lead to geographic variation in survey/collecting effort. We believe that it is likely that the data quality is high and survey effort is relatively consistent across space for swift fox and prairie chicken, given they are large, charismatic animals of high public interest. Thus we feel the occurrence data for these two species is probably reliable and reflects their distributions and relative densities quite well. The data on massasauga occurrence, on the other hand, may be of variable quality given the species' cryptic nature and the typically high spatial variability in survey effort for reptiles. 

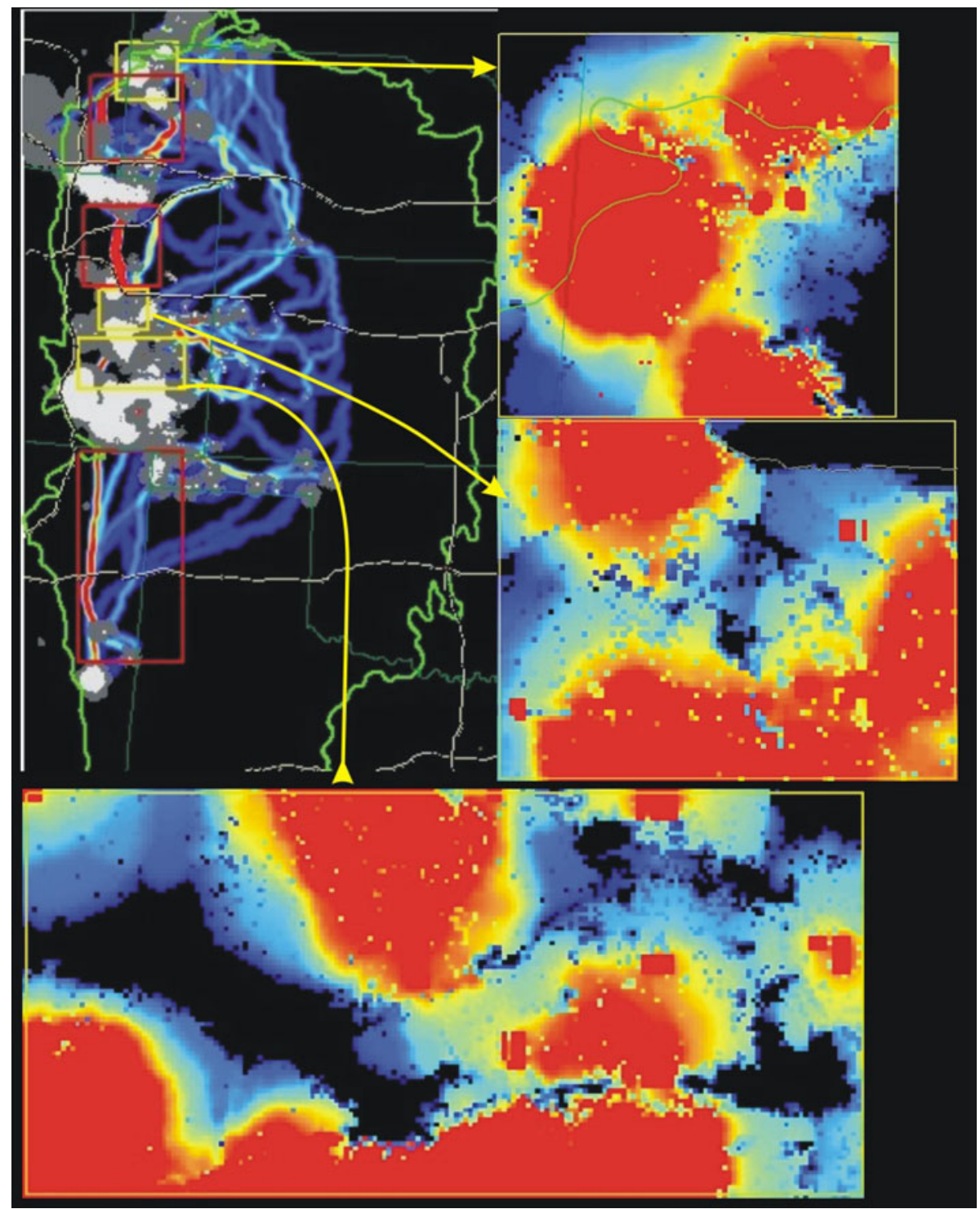

Fig. 5 Key fracture zones for swift fox. The panel at upper left shows the extent of the GPLCC specified by a green outline. State boundaries are shown in dark green and interstate highways are shown as gray lines. The yellow boxes show the locations of the key fracture zones we identified as being particularly important to regional connectivity. The inset panels at right and below show the key fracture zones we identified as most important to maintaining regional connectivity of the swift fox in the GPLCC. The colormap ranges from red (high predicted movement rate) to dark blue (low predicted movement rate). Black areas are predicted to have zero occupancy

A second caveat associated with NatureServe's data concerns the temporal dynamics of populations, particularly in highly fragmented systems like those in the Great Plains. Although the use of occupancy data over the long term (e.g., since 1970) will serve to increase landscape sample coverage, there is a challenge associated with the use of 


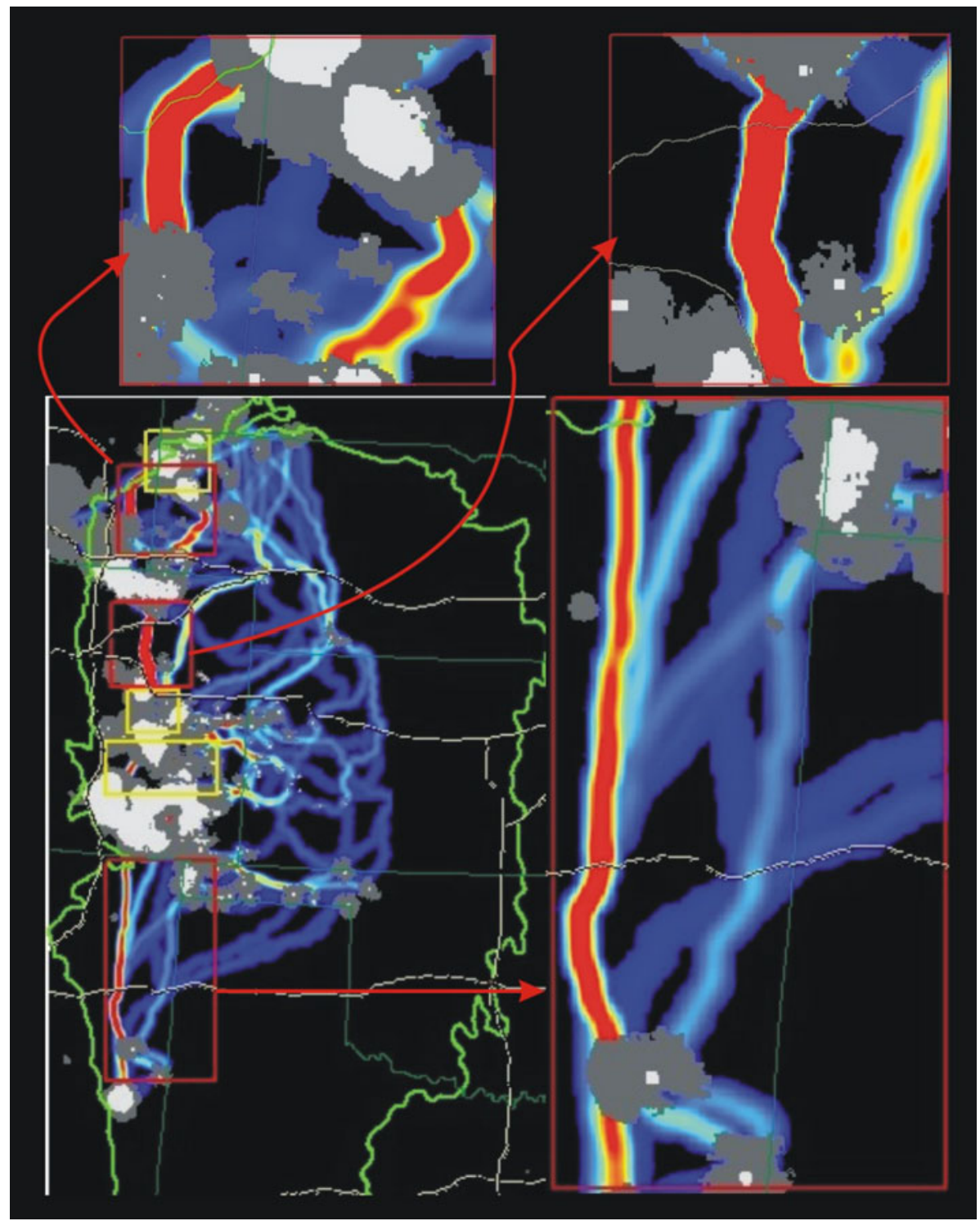

Fig. 6 Key corridors for swift fox. The panel at lower left shows the extent of the GPLCC specified by a green outline. State boundaries are shown in dark green and interstate highways are shown as gray lines. The red boxes show the location of key potential movement corridors between isolated populations. The inset panels at right and above show the key corridors we identified as most important to maintaining regional connectivity of the swift fox. The colormap ranges from red (high corridor strength) to dark blue (low corridor strength). Black areas are predicted to not be part of the predicted corridor

occurrence records over time as to whether they reflect the true current landscape occupancy for the species of interest. Although the habitat layers represent relatively current snapshots, the occurrence data are cumulative since the 1970 s and it is possible that distributional shifts may have occurred such that some of the NatureServe records correspond to locations where the species no longer persist. Therefore, our predictions may not 
reflect the true pattern of occurrence and relative abundance of our focal species, and the degree to which this departure affects the reliability of our predictions is not known. For this reason, the predictions of core habitat areas, fracture zones, and corridors produced by this analysis should be treated as hypotheses that should be subject to further testing before they are utilized to guide management actions. More comprehensive monitoring efforts, both targeted and surveillance (Nichols and Williams 2006; McComb et al. 2010), will serve to improve both our modeling efforts and the testing of their predictions. However, given the geographic scope and the growing number of species of conservation concern, it is likely that unconventional monitoring techniques involving non-invasive genetic sampling will be required if such efforts are to be feasibly implements (Schwartz et al. 2007).

Toward optimized conservation actions

Despite uncertainties associated with our understanding of dispersal ability, landscape resistance, and species occupancy across broad landscapes, our results provide an example of how broad-scale, spatially explicit modeling of core habitat areas (Fig. 5), fracture zones, and corridors (Fig. 6) could inform conservation strategies to maintain or enhance population connectivity for species of conservation concern. Our results suggest a hierarchy of conservation actions that are conditioned on where conservation opportunities fall with respect to core habitat areas, fracture zones, or movement corridors. In core habitat areas, land use incentives that promote habitat retention, conservation easements, or outright acquisition should be pursued. In fracture zones, habitat quality is known to be limiting since movement is more restrictive than in core habitats. Under these circumstances incentives, easements, or acquisition will do little in the absence of habitat restoration efforts that improve habitat quality and facilitate species movement. Finally, areas identified as potential movement corridors must be considered adaptively. Certainly land use restrictions or incentives, land protection, or restoration should be considered within movement corridors, however conservation actions should be couched within an adaptive management framework because of the uncertainty associated with whether species are actually using these predicted movement corridors, and if they are, if the exchange occurs regularly or rarely. Although the potential for strategic conservation planning is great under spatially explicit treatment of species occupancy and movement across broad geographic areas, so too is the potential for squandering limited conservation resources in ways that ultimately fail to improve population connectivity among species of conservation concern. Conservation practice will only overcome the inertia for action by coupling comprehensive occupancy monitoring data, spatially explicit connectivity analyses as outlined here, with real land management planning and implementation-all under the rigors of active adaptive management (e.g., McCarthy and Possingham 2007).

Acknowledgments We gratefully acknowledge the funding assistance provided by the U.S. Fish and Wildlife Service through the Great Plains Landscape Conservation Cooperative and the input provided by James Broska, GPLCC Science Coordinator. We also want to thank the constructive comments provided by two anonymous reviewers that improved our manuscript.

\section{References}

Beier P, Brost B (2010) Use of land facets to plan for climate change: conserving the arenas, not the actors. Conserv Biol 24:701-710 
Beier P, Loe S (1992) In my experience: a checklist for evaluating the impacts to wildlife movement corridors. Wildl Soc Bull 20:434-440

Beier P, Penrod KL, Luke C, Spencer WD, Cabañero C (2006) South coast missing linkages: restoring connectivity to wildlands in the largest metropolitan area in the United States. In: Crooks KR, Sanjayan MA (eds) Connectivity and conservation. Cambridge University Press, Cambridge, pp 555-586

Beier P, Majka D, Bayless T (2007) Linkage designs for Arizona's missing linkages. Arizona Game and Fish Department, Phoenix. http://corridordesign.org/linkages/arizona. Accessed Sept 2009

Berger J, Cain SL, Berger KM (2006) Connecting the dots: an invariant migration corridor links the Holocene to the present. Biol Lett 2:528-531

Clark RW, Brown WS, Stechert R, Zamudio KR (2008) Integrating individual behaviour and landscape genetics: the population structure of timber rattlesnake hibernacula. Mol Ecol 17:719-730

Compton B, McGarigal K, Cushman SA, Gamble L (2007) A resistant kernel model of connectivity for vernal pool breeding amphibians. Conserv Biol 21:788-799

Cushman SA (2006) Effects of habitat loss and fragmentation on amphibians: a review and prospectus. Biol Conserv 128:231-240

Cushman SA, Landguth EL (2010) Scale dependent inference in landscape genetics. Landsc Ecol 25:967-979

Cushman SA, Landguth EL (2012a) Multi-species connectivity in the northern Rocky Mountains. Ecol Model 231:101-112

Cushman SA, Landguth EL (2012b) Ecological associations, dispersal ability, and landscape connectivity in the northern Rocky Mountains. Research Paper RMRS-RP-90. U.S. Department of Agriculture, Fort Collins

Cushman SA, Lewis J (2010) Movement behavior explains genetic differentiation in American black bear. Landsc Ecol 25:1613-1625

Cushman SA, Schwartz MK, Hayden J, McKelvey KS (2006) Gene flow in complex landscapes: confronting models with data. Am Nat 168:486-499

Cushman SA, McKelvey KS, Schwartz MK (2009) Using empirically derived source-destination models to map regional conservation corridors. Conserv Biol 23:368-376

Cushman SA, Chase MJ, Griffin C (2010a) Mapping landscape resistance to identify corridors and barriers for elephant movement in southern Africa. In: Cushman SA, Huettman F (eds) Spatial complexity, informatics, and wildlife conservation. Springer, Tokyo, pp 349-368

Cushman SA, Compton BW, McGarigal K (2010b) Habitat fragmentation effects depend on complex interactions between population size and dispersal ability: modeling influences of roads, agriculture and residential development across a range of life-history characteristics. In: Cushman SA, Huettman F (eds) Spatial complexity, informatics, and wildlife conservation. Springer, Tokyo, pp 369-387

Cushman SA, Gutzwiller K, Evans JS, McGarigal K (2010c) The gradient paradigm: a conceptual and analytical framework for landscape ecology. In: Spatial complexity, informatics, and wildlife conservation. Springer, Japan, pp 83-108

Cushman SA, Landguth EL, Flather CH (2012) Evaluating the sufficiency of protected lands for maintaining wildlife population connectivity in the U.S. northern Rocky Mountains. Divers Distrib 18:873-884

Cushman SA, McRae B, Adriansen F, Beier P, Shirley M, Zeller K (2013) Biological corridors and connectivity. In: MacDonald D (ed) Conservation in theory and practice, Wiley, New York

Dark-Smiley DN, Keinath, DA (2003) Species assessment for swift fox (Vulpes velox) in Wyoming. United States Department of the Interior, Bureau of Land Management, Wyoming State Office, Cheyenne, Wyoming

Dijkstra EW (1959) A note on two problems in connexion with graphs. Numer Math 1:269-271

ESRI (2008) Environmental systems research incorporated. ESRI, Redlands

Fry JA, Coan MJ, Homer CG, Meyer DK, Wickham JD (2009) Completion of the National Land Cover Database (NLCD) 1992-2001 Land cover change retrofit product: U.S. geological survey open-file report 2008-1379

Haddad NM, Bowne DR, Cunningham A, Danielson BJ, Levey DJ, Sargent S, Spira T (2003) Corridor use by diverse taxa. Ecology 84:609-615

Hagen CA, Giesen KM (2005) Lesser prairie-chicken (Tympanuchus pallidicinctus). In: Poole A (ed) The birds of North America online. Cornell Laboratory of Ornithology, Ithica, NY. http://bna.birds.cornell. edu/bna/species/364. Accessed 3 August 2013

Harris LD, Gallagher PB (1989) New initiatives for wildlife conservation: the need for movement corridors. In: Mackintosh G (ed) Preserving communities and corridors. Defenders of Wildlife, Washington, DC, pp 11-34

Harrison S, Bruna E (1999) Habitat fragmentation and large-scale conservation: what do we know for sure. Ecography 22:225-232 
Hobbs RJ (1992) The role of corridors in conservation: a solution or bandwagon. Trends Ecol Evol 7:389-392

Kamler, JF, Ballard WB, Gese EM, Harrison RL, Karki SM (2004) Dispersal characteristics of swift foxes. USDA National Wildlife Research Center-Staff Publications. Paper 339

Landguth EL, Hand BK, Glassy J, Cushman SA (2012) UNICOR: a species connectivity and corridor network simulator. Ecography 35:9-14

Li Q, Racine JS (2007) Smooth varying-coefficient nonparametric models for qualitative and quantitative data (unpublished manuscript)

Mackessy SP (2005) Desert massasauga rattlesnake (Sistrurus catenatus edwardsii): a technical conservation assessment (online). USDA Forest Service, Rocky Mountain Region. http://www.fs.fed.us/r2/ projects/scp/assessments/massasauga.pdf. Accessed 3 August 2013

McCarthy MA, Possingham HP (2007) Active adaptive management for conservation. Conserv Biol 21:956-963

McComb BC, Zuckerburg B, Vesely D et al (2010) Monitoring animal populations and their habitats a practitioner's guide. CRC Press, Boca Raton

McGarigal K, Cushman SA (2005) The gradient concept of landscape structure. In: Wiens J, Moss M (eds) Issues and perspectives in landscape ecology. Cambridge University Press, Cambridge, pp 112-119

McGarigal K, Cushman SA, Neel MC, Ene E (2002) FRAGSTATS: spatial pattern analysis program for categorical maps. Computer software program produced at the University of Massachusetts, Amherst. www.umass.edu/landeco/research/fragstats/fragstats.html. Accessed 3 August 2013

Mercure A, Ralls K, Koepfli KP, Wayne RK (1993) Genetic subdivisions among small canids: mitochondrial DNA differentiation of swift, kit, and arctic foxes. Evolution 47:1313-1328

Neilson RP, Drapek RJ (1998) Potentially complex biosphere responses to transient global warming. Glob Chang Biol 4:505-521

Nichols JD, Williams BK (2006) Monitoring for conservation. Trends Ecol Evol 21:668-673

Reding DM, Cushman SA, Gosselink TE, Clark WR (2013) Linking movement behavior and fine-scale genetic structure to model landscape connectivity for bobcats (Lynx rufus). Landsc Ecol 28:471-486

Robb LA, Schroeder MA (2005) Greater prairie-chicken (Tympanuchus cupido): a technical conservation assessment (online). USDA Forest Service, Rocky Mountain Region. http://www.fs.fed.us/r2/projects/ scp/assessments/greaterprairiechicken.pdf. Accessed 3 August 2013

Rosenberg DK, Noon BR, Meslow EC (1997) Biological corridors: form, function, and efficacy. Bioscience 47:677-687

Rudnick DA, Beier P, Cushman SA, Dieffenbach F, Epps CW, Gerber L, Hartter J, Jennes J, Kintsch J, Merelender AM, Perkl RM, Preziosi DV, Ryan SJ, Trombulak SC (2012) The role of landscape connectivity in planning and implementing conservation and restoration priorities. Issues Ecol 16:1-20

Schwartz MK, Luikart G, Waples RS (2007) Genetic monitoring as a promising tool for conservation and management. Trends Ecol Evol 22:25-33

Seoane J, Bustamante J, Diaz-Delgado RC (2005) Effect of expert opinion on the predictive ability of environmental models of bird distribution. Conserv Biol 19:512-522

Shirk A, Wallin DO, Cushman SA, Rice RC, Warheit C (2010) Inferring landscape effects on gene flow: a new multi-scale model selection framework. Mol Ecol 19:3603-3619

Short Bull RA, Cushman SA, Mace R, Chilton T, Kendall KC, Landguth EL, Schwartz MK (2011) Why replication is important in landscape genetics: American black bear in the Rocky Mountains. Mol Ecol 20(6):1092-1107

Simberloff D, Farr JA, Cox J, Mehlman DW (1992) Movement corridors: conservation bargains or poor investments? Conserv Biol 6:493-504

Spear SF, Balkenhol N, Fortin MJ, McRae BH, Scribner K (2010) Use of resistance surfaces for landscape genetic studies: considerations for parameterization and analysis. Mol Ecol 19:3576-3591

Wasserman TN, Cushman SA, Schwartz MK, Wallin DO (2010) Spatial scaling and multi-model inference in landscape genetics: Martes americana in northern Idaho. Landsc Ecol 25:1601-1612

Wiens JA (2001) The landscape concept of dispersal. In: Clobert J, Danchin E, Dhondt AA, Nichols JD (eds) Dispersal. Oxford University Press, New York, pp 96-109

With KA, Gardner RH, Turner MG (1997) Landscape connectivity and population distributions in heterogeneous environments. Oikos 78:151-169

Zeller KA, McGarigal K, Whiteley AR (2012) Estimating landscape resistance to movement: a review. Landsc Ecol 27:777-797 